\title{
Comparative Physiology of the Respiratory System in the Animal Kingdom
}

\author{
Olga Carvalho* and Carlos Gonçalves
}

\author{
Institute of Histology and Embryology, Medicine Faculty, University of Coimbra, Rua Larga, 3004-504 Coimbra, \\ Portugal
}

\begin{abstract}
The inconstant environment in which animals lives and the variation of their metabolic states determined the gas exchangers system that must be able to operate efficiently across a spectrum of conditions that range from resting to exercise and even under hypoxia. The primordial respiratory organs that evolved for water breathing were the gills, evaginated gas exchangers, whereas for terrestrial air breathing developed a invaginated gas exchangers, the lungs. Specialized organs evolved for animals that can extract oxygen from water and air, consider as a transitional breathing (or bimodal). From amphibians to mammals, it is possible to verify that the dimensions of their respiratory units are being increasingly smaller and the number per unit of lung volume increases. The evolution of the vertebrate respiratory system achieved its most efficient state in birds, with their constant volume parabronchial lungs and their highly compliant air sacs with low pressure ventilation that, enabling them to sustained flapping flight. In contrast, the mammalian bronchoalveolar lungs, with their mandatory high-pressure ventilation and great volume changes, allowed the development of adaptations that favour, for example, a highly mobile trunk for high velocity running predators or to live in a deep-sea.
\end{abstract}

Keywords: Respiratory system, lung development, morphology, alveoli.

\section{INTRODUCTION}

Different points of view have shaped the scientific study of the origin of life. Some of these argue that primeval life was based on simple anaerobic microorganisms able to use a wide inventory of abiotic organic materials (heterotrophic origin), whereas others invoke a more sophisticated organization, one that thrived on simple inorganic molecules (autotrophic origin) [1].

The organization and mechanisms allowing a chemical system to be materially and energetically connected with the environment, and equipped with the ability to self-construct, emerged first, and then appeared the complex chemical structures that provide the system with a temporal connection throughout successive generations. Thus, the origin of life was a process initiated within ecologically interconnected autonomous compartments that evolved into cells with hereditary and true Darwinian evolutionary capabilities [1].

Nevertheless there is a consensus that life started in an anaerobic environment in the so called "primordial broth", a mixture of organic molecules in the absence of oxygen [2].

Molecular phylogenetic studies have revealed a tripartite division of the living world into two procaryotic groups, Bacteria and Archae, and one eukaryotic group, Eucarya. To know which group is the most "primitive" would help to delineate the characters of the last common ancestors to all living beings. According to several investigators and to the procaryotic dogma, the universal ancestor was probably a

*Address correspondence to this author at the Instituto de Histologia e Embriologia, Faculdade de Medicina da Universidade de Coimbra, Rua Larga, 3004-504 Coimbra, Portugal; Tel: 00 (351) 239 857700; E-mail: omcarvalho@gmail.com thermophile because primitive Earth was hotter than today [3]. Nevertheless it is possible that the ancestor would have been a mesophile and, in this case, the root of the tree of life should be located in the eucaryal branch, with Archae and Bacteria sharing a common ancestor [3].

Almost four billion years ago, living beings that inhabited the earth were very primitive microorganisms, perhaps methanogenic bacteria, living in absolute anaerobiosis [4]. These organisms still exist in our days and are included in the Archae domain, and for this reason are central to the paleoenvironment and paleobiology studies [5].

Anaerobic fermentation was a very inefficient metabolic process of extracting energy from organic molecules and the rise of an oxygenic environment was a momentous event in the diversification of life that dramatically shifted from inefficient to sophisticated oxygen dependent oxidizing ecosystems. Subsequently, oxygen became an indispensable factor for aerobic metabolism, especially in the higher life forms.

There are two widely accepted views of aerobic metabolism: first, that it was only possible after oxygen release by photosynthesis became abundant, and second, that it developed independently in diverse evolutionary lines. Analysis of the temporal distribution and geochemistry, suggest that the transition from reducing to sable oxygenic environment occurred later, between 2.3 and 1.8 billion years ago [6].

Molecular evidence shows that aerobic respiration evolved before oxygenic photosynthesis, or, in other words, cytochrome oxidase appeared before the water-splitting system. This hypothesis considers that denitrification (NO reductase) is the probable origin of aerobic respiration, that aerobic respiration arose only once the last universal ancestor was already present and that oxygenic photosynthesis developed 
in a single evolutionary line, the cyanobacteria, after the origin of aerobic respiration [7].

The rise of atmospheric oxygen caused by photosynthetic activity of evolving cyanobacteria must have created a remarkably strong selective pressure on organisms in both domains. Adaptations to use the new, chemically superior, electron receptor might have taken place, with similar molecular solutions creating the oxygen-reducing active sites. This would mean that the aerobic respiration has a single origin and may have evolved before the oxygen was released to the atmosphere by photosynthetic organisms and that the appearance of aerobic respiration was polyphyletic [7].

This new and more profitable method of extracting energy, aerobic respiration, should have led to a domain of aerobic organisms in the biological community, and probably even leading to the extinction of some anaerobic organisms $[8,9]$.

The evolution to multicellular organisms determined the appearance of more sophisticated and specialized systems for the gas exchange, in order to develop an effective system of exchange. The existence of multicellular organisms, led to rapid and progressive morphofunctional differentiation of groups of cells that became the precursors of tissues, organs and systems currently present in more complex organisms. In most cases, this cellular specialization does not imply the loss of genetic material but only changes in the genes expression $[9,10]$.

The respiratory systems from different groups of animals, although morphologically different, have in common the following characteristics: they have a large capillary network, the gas exchange surfaces are thin and moist; constant renewal of oxygen-rich fluid (air or water) order to provide oxygen and remove carbon dioxide; free movement of blood within the capillary network $[11,12]$. According to Atwood, the assumptions stated above, are present either external respiration is carried out by 1) cutaneous diffusion (earthworm and some amphibians), 2) by thin tubes called tracheae (some insects); 3) by gills, the respiratory system of fish or 4) by diffusion through the lungs, respiratory organs present in amphibians, reptiles, birds and mammals [13].

\section{RESPIRATORY ORGANS IN VERTEBRATES}

The steps of the evolution of terrestrial vertebrates are: change from anaerobic to aerobic life, accretion of unicells into multicellular organs, formation of a closed circulatory system, evolution of metal-based carrier pigments that improved oxygen up-take, formation of invaginated respiratory organs, physical translocation from water to land, development of a double circulation and progression from ectothermic-heterothermy to endothermic-homeothermy [14].

In vertebrates, the blood performs the task of transporting oxygen to the cells and carbon dioxide to the external environment [15].

The development of the respiratory organs of vertebrates is closely related to the primitive pharynx, since the gills of aquatic vertebrates and the lungs of terrestrial vertebrates and aquatic mammals have pharyngeal embryology origin $[16,17]$.
In all vertebrates, at a certain stage of their development, arise bilaterally in craneo-caudal direction from the inner side of the pharynx, a series of diverticula, which evaginate towards the outer surface, forming the pharyngeal pouches $[16,17]$. The number of pharyngeal pouches is greater in lower vertebrates, reaching fourteen in cyclostomes and only four or five in birds and mammals. The pharyngeal pouches are separated by masses of mesenchyme that have the designation of pharyngeal arches, in which is located an arterial structure, called the aortic arch, which extends from the ventral aorta to the dorsal aorta $[16,17]$.

During the ontogenesis of higher vertebrates, the pharyngeal pouches fail to open to the outside, contrarily to what happens in fish and, temporarily, in amphibians. Thus, in higher vertebrates, the pharyngeal pouches just remain during the embryonic period, where they undergo several changes, but very few or none of their initial characteristics are presented in adults. In amniotes, as in humans, only the first pair of pharyngeal pouches remains, giving origin bilaterally, the eustachian tube and middle ear [16, 17].

\section{RESPIRATORY SYSTEM IN FISH}

The fish gill adapted a structure for extraction of oxygen from water that is formed by a large number of filaments spaced out along the gill arches on either side of the pharynx. Each filament has a series of plates projecting at right angles from its upper and lower surfaces, the secondary lamellae, which are extremely numerous, are the site of gaseous exchange and form a fine sieve which ensures that all the water comes into close contact with the blood $[2,18]$.

The gills are multifunctional organs that are responsible for the gas exchange (respiration) but also for the osmoregulation, acid-base regulation, and excretion of nitrogenous waste [18, 19].

The epithelial surface of a gill arch is structurally and functionally zoned [2]. The filaments are covered by two distinct epithelial surfaces, the lamellar and filament epithelia, also termed the secondary and primary epithelia respectively [20]. Gas exchange occurs through the secondary lamellae, and the non-respiratory functions of the gills take place in the primary epithelium [2].

The primary epithelium contains the chloride cells, which vary in morphology and number according to the milieu where the fish lives. The presence of an accessory cell beside the chloride cell is characteristic of seawater or seawateradapted fish [20]. The secondary epithelium that covers the free part of the secondary lamellae has an exclusive relationship with the arterioarterial vasculature, i.e., the pillar cells. This epithelium consists of an outermost layer of pavement cells that exhibits structural characteristics suggestive of cell coat secretion and an innermost layer of less differentiated cells. In contrast to the primary epithelium, the secondary epithelium does not exhibit any obvious differences between freshwater and seawater fish [20].

The lamellar structure helps to increase the surface area but depends on the following complex anatomy to maintain the flat space necessary for circulation: separation between epithelial sheets (by pillar cells) and connection between the 
basal lamina of epithelial sheets by groups of strands (collagen columns) [21].

To prevent ballooning and to ensure the sheet-flow dynamics of blood, the two layers of respiratory epithelium are connected by many strands of extracellular matrix (ECM) materials, which are called collagen columns [21]. These columns, made of collagen fibers, are essential for reinforcing the lamellae structure and the internal force of blood pressure [21]. Since collagen triggers the coagulation cascade when exposed to blood, the collagen columns are surrounded by the plasma membrane of pillar cells, which isolate them from circulation $[22,23]$.

In the interface between pillar cells and collagen columns, exist adhesion junctions termed as "column junctions" and "autocelullar junctions", both of which are essential constituents of the gill lamellae [24]. The "column junctions" is a cell-ECM adhesion and "autocelullar junctions" a membrane-membrane adhesion, both involved in maintaining structural integrity and hemodynamic of branchial lamellae [24].

The pillar cells have a spool-shape and possess a cylindrical cell body connecting two parallel sheets of respiratory epithelium [22, 23]. They also enfold 5 to 8 collagen columns and have numerous myofilaments, parallel to the collagen columns, which consist of actin [21, 25] and myosin [21], which form the contractile apparatus of the cell.

The pillar cells are a type of endothelial cells that delimits a network of vascular compartments within the lamellae of gill fish, but since they share characteristics with smooth muscle cells, we can say that these cells are specialized vascular cells with characteristics of both endothelial and smooth muscle cells [21].

The contractile apparatuses of the pillar cells possibly prevent collagen columns from being stretched and provide plasticity to the vascular network of the lamella against changes in blood pressure [21]. Other possible function for the contractile structures of the pillar cells is that they can change the diameter of the vascular channels, and therefore contribute to the regulation of blood flow through the lamellae $[2,21]$.

Besides the pillar cells, the gill epithelium of freshwater fishes have pavement cells (also termed as respiratory cells in older literature), mucus cells, neuro-epithelial cells and chloride cells [20].

The neuroepithelial cells are isolated or clustered on the internal side of the primary lamellae facing the respiratory water flow [26]. They are probably involved in local and central modulation of the branchial functions by interacting with the branchial nervous system and by paracrine secretion of substances such as serotonin [27]. These cells share several morphofunctional features with the cells of the neuroepithelial bodies in the lungs of air-breathing vertebrates $[26,27]$.

The chloride cells are described as large, granular, acidophilic and mitochondria-rich cells [28] and exhibit an extensive tubular system emanating from the basolateral membrane, an array of sub-apical vesicles, large ovoid nucleus and abundance of $\mathrm{Na}^{+}, \mathrm{K}^{+}$-ATPase enzyme [19]. There is a marked difference between species in the structure of the apical membrane of chloride cells which precludes their absolute identification [19].

They are located in the primary epithelium in close proximity to the blood vessels [2, 19] and are sites of active chloride secretion and high ionic permeability [28], performing an integral role in acid-base regulation [19]. As in other vertebrates, fish must maintain homeostasis of intra and extracellular $\mathrm{pH}$ and therefore use the parallel strategies of buffering and excretion to defend against $\mathrm{pH}$ changes [29]. During alkalosis conditions, the area of exposed chloride cells is increased, which serves to enhance base equivalent excretion as the rate of $\mathrm{Cl}-/ \mathrm{HCO}_{3}$ - exchange is increased. Conversely, during acidosis, the chloride cells surface area is diminished by an expansion of the adjacent pavement cells, and this response reduces the number of functional $\mathrm{Cl}-/ \mathrm{HCO}_{3}$ - exchangers [19].

Under softwater or toxic conditions, chloride cells proliferate on both surfaces of the gill and might impair gas transfer owing to a thickening of the lamellar blood-to-water diffusion barrier [19].

Water enters through the fish's mouth and out through the gill, slits in a direction that is opposite to the blood flow in the gill, providing a constant renewal of the oxygen supply in contact with the respiratory organ $[18,30]$.

The exchange of oxygen and carbon dioxide takes place by diffusion from the surrounding water and the blood that flows within the capillary network of the gills, and because of this countercurrent flow fish can extract 80 to $90 \%$ of dissolved oxygen in water [30].

During the larval development of fish, the teleosts in particular, the skin is the cutaneous surface that ensures gas exchange, and only in the final stage of this period begins the hematosis through the gills [31], when the muscle-skeleton structure of the oral cavity becomes able to coordinate food intake with the flow of water through the branchial system [32].

\section{Lungfishes}

Changing conditions of life imposed new requirements on the morphology and physiology of the organisms. One of these changes is the evolutionary transition from aquatic to terrestrial life, leading to adaptations in locomotion, breathing, hearing, mechanism for food capture and other functions (Fig. 1).

The first air-breathing vertebrates were fishes, and a Devonian air-breathing sarcopterygian (lobefin) occupies the basal position in the lineage extending from the Paleozoic fishes to the most derived tetrapods $[33,34]$.

The evolution of tetrapods from sarcopterygian fish is one of the major transformations in the history of life and involved numerous structural and functional innovations. The Styloichthys changae, one fossil of sarcopterygian fish, exhibits the character combination in a stem group close to the last common ancestor of tetrapods and lungfish [35].

The recent discovery of a well-preserved species of fossil sarcopterygian fish form in the late Devonian of Artic Canada, that represents an intermediate between fish with fins and tetrapods with limbs, provides unique insights into 


\section{Fish}

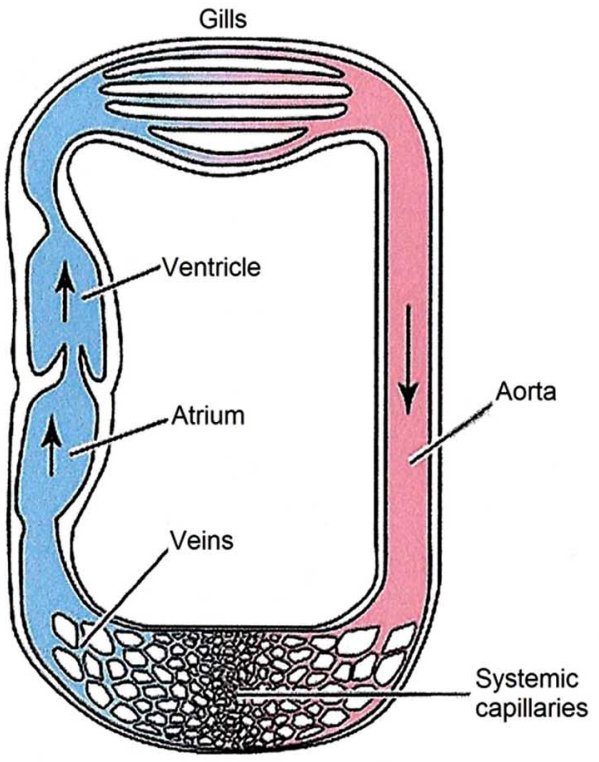

Fig. (1). Blood flow in oxygenation system in fish and lungfish.

how and in what order important tetrapod characters arose [36]. The morphological features and geological setting of this new animal are suggestive of life in shallow-water, marginal and subaerial habitats [36].

The relevance of the extant air-breathing fishes as models for events in the Paleozoic has been a recurring theme for more than one century. The lungfish is considered homologous to the lungs of all higher vertebrates and the precursor of the enteleost gas bladder [34, 37].

In our days the lungfish are represented by three genera, the Australian lungfish, Neoceratodus forsteri, and the other two genera: the African (Protopterus) and South American (Lepidosiren) lungfish [38].

The Australian Neoceratodus differ from the other lungfish because they breathe air for short periods and for this reason the lung is an accessory organ which is only used during periods of high activity in its natural habitat $[39,40]$. They have efficient gills and possess only a single lung, unlike both Protopterus and Lepidosiren which have paired lungs and much reduced gills [41, 42].

The lung of N. forsteri consists of a single elongated chamber compartmentalized by a thick cartilaginous structural framework [40]. The epithelial lining of these supporting structures comprised abundant capillaries interspersed with cells resembling alveolar type II and type I cells. These epithelial cells which appear to be the only cell type lining the gas-diffusing surface [40], have long cytoplasmic plates bearing microvilli, which form part of the gas-exchange membrane. The cells contain large numbers of osmiophilic bodies resembling mammalian lamellar bodies, and it is possible that these lungfish cells may be the common ancestral cell for the alveolar type I and II found in the mammalian lung [40]. They also have a surfactant-like material containing both SP-A and SP-B like proteins,

\section{Lungfish}

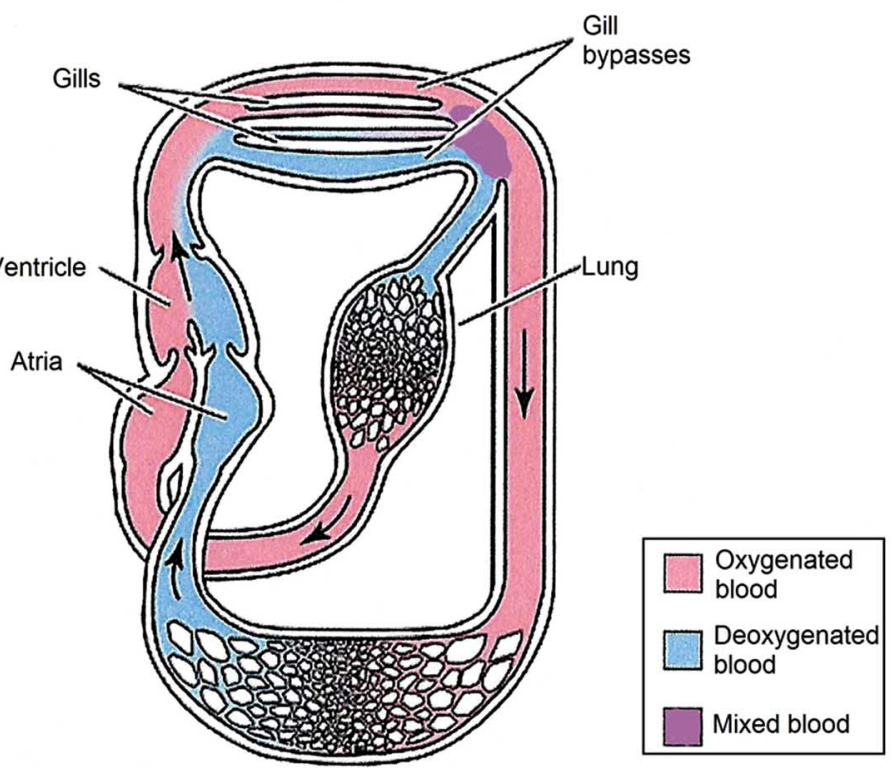

suggesting that even in this primitive lung, these proteins are still involved in surfactant homeostasis [40].

To breathe air the Neoceratodus may rise to surface, exhale through the mouth, inhale and dive forward or rise to the surface, breathe and reverse back into the water [39].

Protopterus and Lepidosiren are bimodal breathers, that use both gills and lungs for respiratory gas transfer, but they are obligate breathers because they die if denied access to air $[43,42]$. The Protopterus occupy a variety of habitats both lentic (standing water) and lotic (running water) [43] and possess the capacity to aestivate, reducing their metabolic rate, which allow them to survive to extreme heat or for long dry periods [43-45]. In the Protopterus, the gills and skin uptake only $10 \%$ of the total $\mathrm{O}_{2}$ uptake and these structures are much more effective in removing the $\mathrm{CO}_{2}[46]$.

The reedfish Calamoichthys calabaricus is one of the phylogenetically most primitive extant air-breathing fishes, and represents an animal successfully adapted not only for air breathing but also for making short-term use of terrestrial environments. In this primitive living actinopterygian fish the oxygen uptake is achieved by the gills, skin and a paired lungs and in the total volume oxygen uptake, the lungs account for $40 \%$, the gills $28 \%$, and the skin $32 \%$ [47].

In the Lepidosiren $99.15 \%$ of the total diffusing capacity lies in the lungs, $0.85 \%$ in the skin and only an insignificant $0.0013 \%$ in the gills, which shows that the gills don't have any importance as a gas exchange organ in this species. Oxygen uptake is accomplished by the lungs and dioxide carbon is eliminated by the skin [48].

The structure of the gills lamellae of Lepidosiren consists of a stratified epithelium that rests on the basal membrane and has at least three layers of cuboidal cells with large nuclei. Close to the epithelium there are numerous capillaries [48]. 


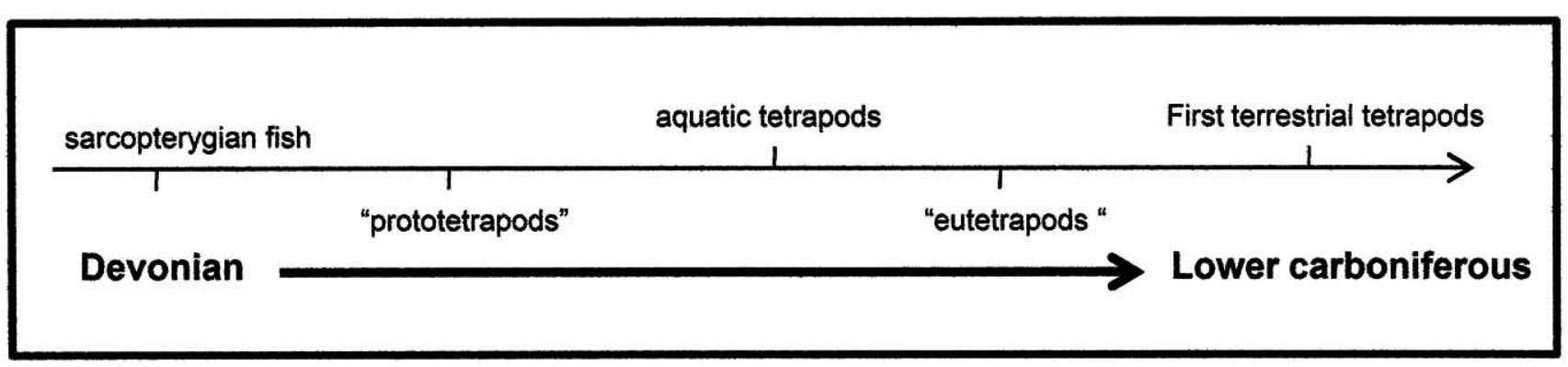

Fig. (2). Tetrapods evolution.

Each lung of these lungfish has a main duct and numerous chambers of different sizes, which decrease in size as they progress caudally. The honeycomb-like edicular parenchyma is disposed in these chambers and most chambers contain a central lumen, which connects with the air duct. The duct, the chambers and edicular parenchyma consist of connective tissue septa held upright by smooth muscular/elastic trabeculae and are supplied and drained by branches of the pulmonary artery and vein. Most interedicular septa have a double capillary net. The air-blood barrier consists of three layers: a simple squamous epithelium made up of a single type of cell, the endothelial cells of the blood capillaries and the combined basal lamina of the epithelial and endothelial cells [48].

The skin of these fish has two layers, the epidermis and the dermis. The epidermis consists of a stratified epithelium with six to ten layers of diverse cell types. Most prominent are superficially located cuboidal cells with a large central nucleus and the mucous cells that are dispersed among the other cell layers. The dermis is a dense connective tissue, with blood vessels and small ossified scales. Numerous blood capillaries and melanophores lie beneath the basal membrane and between the subjacent layers [48].

In the Protopterus and Lepidosiren the ventilation of the gills occurs through the action of a positive pressure buccal pump anterior to the gills and an opercular suction pump posterior to the gills. These pumps generate a nearly continuous water pressure gradient favouring a water flow in the mouth, through the gills and out the opercular opening [42]. The ventilation of the lungs in Protopterus is achieved by the same musculoskeletal elements involved in aquatic ventilation, the buccal force pump mechanisms [42].

Early in their history, fish developed supplementary air breathing organs in two taxonomic lines - Actinopterygians and Sarcopterygians [37]. The onset of aerial respiration in primitive fish was an important milestone in the evolution of terrestrial vertebrates.

The fish-tetrapod transition was one of the greatest events in the vertebrate evolution. Tetrapods first appeared in the late Devonian about 360 million years ago, but appear to have been primarily aquatic animals [49]. For some investigators the freshwater origin of tetrapods remains the most likely scenario, but several recent findings raise the possibility that the tetrapod land invasion could come from a marine habitat [50].

The evolution of tetrapods occured under environmental influences and presumption that hypoxia habitat conditions were similar to those commonly encountered in tropical lowland habitats during dry seasons [51].

The sequence of evolution begun with sarcopterygian fish, followed by the appearance of a "prototetrapods" (e.g. Elginerpeton), the emergence of aquatic tetrapods (e.g. Acanthostega), the appearance of "eutetrapods (e.g. Tulerpeton) and the first truly terrestrial tetrapods (e.g. Pederpes) in the lower Carboniferous [49]. Several morphological changes were observed during the evolution process, developing specialized features that allowed land locomotion and air breathing (Fig. 2) [49].

The sudden change from gill respiration to lung breathing would pose considerable physiological problems. One of the consequences of gill loss, would be the concentration of respiratory $\mathrm{CO} 2$ within the body, which required buffering by bicarbonate ion and affected processes such as acid-base balance, $\mathrm{O} 2$ binding by haemoglobin, ventilation rate, respiratory control and also affected nitrogen excretion, ion regulation and water balance, vital processes that would need to be assumed by others organs.

The advantages of tetrapod gill loss included head mobility, development of hearing and the origin of different ventilatory and feeding mechanisms $[49,50]$.

In the primitive pure buccal pumping, found in most airbreathing fishes, including lungfishes, the axial musculature does not contribute to expiration or inspiration. In fact, the buccal pump breathing has been proposed to constrain the evolution of tongue morphology and head shape [52].

The aspiration breathing was present in some early tetrapods, but it only arised when the early amniotes appeared. Aspiration breathing evolved in two steps: first, from pure buccal pump breathing to the use of axial muscles for expiration and buccal pump for inspiration; second, to pure aspiration-breathing, in which axial muscles are used for both expiration and inspiration [52].

The musculoskeletal units responsible for breathing also serve other functions such as feeding or locomotion, and the conflicting mechanical requirements of multiple functions possibly constrain the performance and evolution of one or both functions. The evolution of aspiration breathing may have allowed the musculoskeletal systems of the head and tongue of amniotes to diversify, but the ribs and intercostal musculature became constrained by their dual function in aspiration breathing and high speed locomotion $[37,52]$.

The loss of gills is also in connexion to the cutaneous respiration as a site gaseous exchange which can function in water and land. 
So, the possible evolution of the respiratory mechanisms maybe begun with an ancestral fish adapted for oxygen uptake and $\mathrm{CO}_{2}$ elimination in aquatic medium, but under conditions of low oxygen, developed adaptations that allowed the fish to come to the surface to obtain extra oxygen from the air, but the gills still functioned for $\mathrm{CO}_{2}$ elimination.

At this stage of evolution, the skin would function mainly for $\mathrm{CO}_{2}$ elimination and, as the lung became more efficient and more involved, not only in uptake of oxygen but also in elimination of carbon dioxide, the skin became less important and probably covered with hardened scales to reduce water loss and the animal could now remain away from water for longer periods [53]. It seems possible to accept that the cutaneous respiration was important for the earliest land vertebrates [53].

\section{RESPIRATORY ORGANS IN AMPHIBIANS}

Based on paleontological criteria, the first amphibians have arisen by evolution of fish Crossopterigeos ripidistios, extinct in the late Devonian period [11].

Modern amphibians occupy a central position in understanding the fundamental changes that have occurred in the evolution of air breathing. Dual subsistence in water and land has required development of certain respiratory adaptations.

The transition from aquatic to land environment exposed the gas exchange organ to a much richer oxygen ambience, which allowed a drastic reduction in the ventilation requirements, but at the same time created problems for the disposal of carbon dioxide, because at $20^{\circ} \mathrm{C}$ the water solubility of this gas is 28 times greater than that of oxygen [54].

To prevent a severe respiratory acidosis, the Terran animal began to use the skin as an important respiratory organ, designed especially for the removal of carbon dioxide, which required a substantially reduction of the barrier represented by the scales that covered the surface of their aquatic ancestors. At the same time there must have occurred an increased bicarbonate concentration in plasma, in order to compensate the increase of carbon dioxide [55].

These animals are mainly characterized for presenting an aquatic larval form, the tadpole stage, where hematosis takes place through the gills. Next they suffered a metamorphosis that allowed them to reach adulthood in terrestrial habitat and in which the breathing air was carried out by the lungs, skin and mouth [56]. The amount of cutaneous and buccal gas exchange and its percentage in the total gas exchange, varied from species to species and also during seasons [37, $55,57]$.

Amphibians have the simplest lungs, rudimentary lungs that are adequate for ectothermic and low aerobic metabolism animals [14].

The paired lungs of recent amphibians are unicameral lying in the dorsal pleuroperitoneal cavity. In the various amphibian species the lungs differ greatly in size, their topographic extension and the dimension of exchange surface by the development of interconnected folds with highly varying number of subdivisions and height of their folds [37]. The highly varying extent in lung exchange is due to differences in the amount of gas exchange performed by via lungs in concert with cutaneous and buccal cavity exchange [37]

Moreover, the absence of an individualized chest well, with no ribs or diaphragm, the amphibian's pulmonary ventilation is mainly accomplished at the expense of swallowing air, carried out by rising of the oral cavity floor [58].

The remarkable heterogeneity of the morphology of the amphibian gas exchangers matches that of the diversity of the environments in which the animals live, the lifestyle they pursue, and their pattern of interrupted development. The skin is the main pathway for gas transfer in aquatic species while in terrestrial ones, it has been relegated or rendered redundant [14].

In the salamanders (Plethodontidae), some of which live in cold well-aerated waters, gas exchange occurs across the skin and buccal cavity [59]. Skin breathing is important in all extant amphibians but is the only means of gas exchange in those salamanders (terrestrial and aquatic) which possess neither lungs nor gills. Gas exchange takes place in the dense subepithelial capillary network, the inflow to which is in part from the arterial system and in part from a branch of the pulmonary arch carrying venous blood. The oxygenated cutaneous blood flows into the venous system. This is in contrast to the arrangement of pulmonary outflow in tetrapods and lungfish which allows (complete or partial) separation of oxygenated from venous blood [60].

The caecilians (Apoda) possess long, tubular lungs, but in some species the left lung is remarkably reduced or totally missing [61]. The lungs of caecilians are internally subdivided, forming air cells that are supported by diametrically placed trabeculae.

In the newts (Urodela), animals that are mostly aquatic, the lungs are poorly vascularised with the internal surface being smooth. Lungs of most amphibians such as Amphiuma tridactum and the cane toad, Bufo marinus, have an abundance of smooth muscle tissue [62], a feature that may explain the high compliance of the lungs [63]. In Amphiuma, during expiration, the lung virtually collapses, producing an almost $100 \%$ turn-over of inspired air [62]. Amphiuma is aquatic but has very well developed lungs.

The lungs of terrestrial species are highly elaborate presenting a series of stratified septa that divided the lung into small air cells and the lungs of Anura and Apoda are more complex than those of Urodela [14].

\section{RESPIRATORY ORGANS IN REPTILES}

It is assumed that reptiles made their appearance on Earth about 310 million years ago, and their adaptation was so perfect that they dominated the planet for over a hundred million years. The innumerous fossils that have been discovered allow us to group them in a numerous orders capable for living in different habitats, such as land, air or aquatic environment.

Reptilians are the first vertebrates adequately adapted for terrestrial habitation and utilization of lungs as a sole pathway for acquisition of oxygen [14]. The skin that was no 
longer necessary for gas exchange, became an armor to protect against dehydration [55], being waterproof, dry, covered with keratinized epidermal scales or developing dermal bone plates [56].

Compared with their gigantic prehistoric ancestors, current reptiles are small and insignificant and can be grouped in four orders: chelonians, such as turtles and tortoises; rincocéfalos, like Sphenodon of New Zealand; crocodiles (crocodiles and caimans) and squamata order (lizards and snakes).

The reptilian display great pulmonary structural heterogeneity and there is no single model of reptilian lung. Based on complexity of internal organization, different classification suggested that the turtles, monitor lizard, crocodiles and snakes have a profusely subdivided (multicameral) lung, the chameleons and iguanids have a simpler (paucicameral) lung and the teju lizard (Tupinambis nigropunctatus) have a saccular, smooth-walled, transparent (unicameral) lung [14].

Division of the lumen of the lung into a number of chambers, by septation, enlarges the exchange area, fact that is observed in turtles, lizards and crocodiles [37].

The lungs are localized in the pleuroperitoneal cavity and there is no diaphragm separating the thoracic from the abdominal cavity. Presence of ribs and intercostal muscles in reptiles, allow the development of more effective pulmonary ventilation than that of the amphibians which do not have these anatomical structures.

Generally, the pattern of organization of the respiratory system of reptiles is identical to mammals, with the lungs coated externally by a serosa [64]. The conducting portions are supported by complete cartilaginous rings, which continue through the extra and intrapulmonary bronchi. The branching of the bronchial intrapulmonary tree in reptiles is similar to mammals', however they have specific designations [65], which appear sequentially bronchus, tubular chambers, niches and aedicules.

The intrapulmonary bronchi of the reptiles that give immediate access to respiratory areas correspond to the mammalian respiratory bronchioles, the tubular chambers, according to their position and morphofunctional structure, are equivalent to the alveolar channels in mammals, and the niche are similar to alveolar sacs. By its position in the respiratory system and anatomical constitution the aedicules are equivalent to the alveoli of mammals, however they have an oblong structure compared with the spherical form of mammal's alveoli.

The intrapulmonary bronchi of turtles that live essentially in aquatic environment have a reinforcement that extends to or near the respiratory areas [64], characteristic that is similar to the aquatic mammals that have the ability to dive to great depths, such as seals, dolphins and whales [66]. This reinforcement, along with the presence of a smooth muscle, appear to be adaptations that allow these animals to support the high pressures to which they are subjected during the immersion to great depths.

The epithelium of the trachea and bronchi is pseudostratified columnar ciliated, with non ciliated secretory cells and basal cells, all in direct contact with the basal membrane [67]. Isolated or groups of neuroendocrine cells were also identified within the conducting portion of the lung of turtles [64, 68, 69] and crocodiles [70].

The epithelial cells lining the respiratory surface of reptilian lungs are differentiated into type I and type II cells and it is possible to observe multilamellar bodies [14, 64, 71] similar to those present in mammals $[72,73]$. These suggest that also in reptiles occurs the synthesis of surfactant lipoprotein material responsible for the stability of their respiratory unit, the aedicula [64].

The role of surfactant in reptiles, which are not highly susceptible to collapse from surface tension forces, is obscure, and may have other important functions such as prevention of transendothelial transudation of blood plasma across the blood-gas barrier, immune suppression and attraction of macrophages [2].

Reptilian lungs have preponderance of smooth muscle tissue and this tissue has been associated with intrapulmonary connective movement of air [14].

\section{RESPIRATORY SYSTEM IN BIRDS}

Birds' respiratory system, the lung - air sac system, is the most complex and efficient gas exchanger that has evolved in air-breathing vertebrates. The compact and virtually constant-volume avian lung has been totally uncoupled from the compliant, avascular air sacs.

The main properties that impart high respiratory efficiency on the lung-air sac system of birds are a cross-current design and inbuilt multicapillary serial arterialisation system; auxiliary counter-current system; large tidal volume; large cardiac output; continuous and unidirectional parabronchial ventilation; short pulmonary circulatory time; superior morphometric parameters [14]; a particularly large respiratory surface area and a remarkably thin blood-gas (tissue) barrier [74].

Their respiratory system allows them to breathe at altitudes that can reach nine thousand meters without acclimatization, fact that is impossible for humans and other mammals, in which the barometric pressure of high altitudes can at least induce a comatose state [75-77].

To maintain physiological function at high altitude, under reduced environmental oxygen availability, the capacity to transport $\mathrm{O}_{2}$ must increase. The exposure to hypoxia causes an immediate increase in breathing due to stimulation of arterial chemoreceptors and changes in metabolic state. The ability to adjust peripheral heat dissipation to facilitate the depression of body temperature during hypoxia, which reduced the metabolic demand, allows birds to fly high and for long periods, and is a result of an evolutionary adaptation [78]. The bar-headed goose, a typical high altitude bird, depresses metabolism less than low-altitude birds during hypoxia and breathes substantially more than birds that fly at low altitudes. The bar-headed goose has a haemoglobin with higher $\mathrm{O}_{2}$ affinity and may be capable of generating higher inspiratory airflows [79].

The respiratory system of birds is separated into lung (the gas exchanging part) and a series of airs sacs (non respiratory) with anastomosing air capillaries and pneumatized bones, [30, 37, 80] that allow unidirectional flow of air, 
compared to the blind sac and tidal flow in mammalian lungs $[2,77,81]$.

Lack of diaphragm displaced the lungs to the coelomic cavity where they are closely attached to the ribs [2]. Intercalated between the sacs, the lungs are largely continuously ventilated back-to-front by a concerted action of the cranial and caudal groups of air sacs [2, 37].

There are fundamental differences in the breathing mechanics of different birds, driven in part by the morphological differences of the rib cage and sternum associated with skeletal adaptations to locomotion [82]. The uncinate processes are bony projections that extend from the vertebral ribs, providing attachment sites for respiratory muscles.

The elongation of ribs, rib cage and sternum associated with diving species, as well as longer uncinates, maybe important upon resurfacing when inspiration occurs against the pressure of water against the body [82]. The reduction in the sternum and the shortest uncinate length found in the walking species, suggests that they may play a reduced role during breathing in these species [82].

The circular lumen of the trachea has a cartilaginous or partially ossified support ring, whose number varies according to species [76] and is lined by a cilindric pseudociliated epithelium with goblet cells [83]. The trachea bifurcates into two primary bronchi, with an epithelial lining similar to the trachea but with incomplete cartilaginous rings, which disappear or are reduced when they reach the bronchial lung parenchyma [83].

The pair of lungs of the birds are relatively small, noncompliant [37], localized in the dorsal thorax region and with little moving during breathing, as air is driven unidirectionally though the lung, via the system of air sacs [84].

The connection between the primary bronchus and the secondary and tertiary bronchi is labyrinthic, markedly opposed to the monopodic branch of mammal. The primary bronchus gives rise to four craneo-medium secondary bronchus and to seven caudal-dorsal secondary bronchus [11, 76]. In the secondary bronchus the mucosa is lined by a simple cuboidal or columnar epithelium, without goblet cells [83]. Tertiary bronchus or parabronchus are arranged in a series of parallel lines, whose ends are open to the secondary bronchus. All the way through the parabronchus have recurrent anastomoses between them [77]. The number of parabronchus varies from species to species, but is higher in the birds that fly better [85], has been estimated in Gallus domesticus between 300 and 500 parabronchus [77, 86]. Parabronchus have an average diameter of $500 \mu \mathrm{m}$ [85], and are lined by a simple squamous epithelium [87], just like the mammals' alveolar channels. Along the inner surface of parabronchus, small vesicular structures with hexagonal shape emerge, with 100 to $200 \mu \mathrm{m}$ in diameter [37, 77, 87]. These structures called atria are separated from each other by septa mainly consisting of smooth muscle cells located in the freeboard $[76,87]$, and collagen and elastic fibers, located at the base [87]. The atria epithelium has two types of cells, one of which are the granular cells [87] that are confined to the atria, have a cytoplasm that contains multilamellar bodies and are considered analogous to the cells of type II pneumocytes of the mammal's lungs [88]. The other are the squamous cells, which line the inner surface of the atria and are based on a continuous basal membrane, forming the simple squamous epithelium [89]. From the deepest area of each atria arise 2 to 4 infundibula that continue with the air capillaries with 3 to $10 \mu \mathrm{m}$ diameter $[37,90,91]$. They are lined by squamous cells, that are similar to the cells of the atria, but they are not based on the basal membrane [87]. The infundibula and air capillaries of adjacent atria form anastomosis to one another $[37,77]$.

The blood capillaries are surrounded by extremely small air capillaries and other capillaries, which give an appearance of a dense network. The blood capillaries are embedded in a rigid structure with numerous cross-braces that provide mechanical support of the small vessels at numerous points [92]. This feature contributes to mechanical strength of blood capillaries and allows them to have a remarkably thin blood-gas barrier (BGB) that is uniformly arranged all around the circumference of the blood capillary [92].

The diameters of the air capillaries are comparable to those of blood capillaries and as a consequence of the very small diameter, the surface tension of these air capillaries is so high, despite their very well-differentiated surfactant, that they can only remain patent as rigid structures in a volumeconstant lung [37]. The surfactant of these rigid air capillaries lowers the high air capillary surface tension to such an extent that the remaining surface tension cannot suck fluid from the blood into the air capillary, thus preventing edema and maintaining gas exchange [37].

Together with the extensive network of blood capillaries, the air capillaries form the gas exchange surface of the bird's lungs.

Unlike those observed in lung alveoli of mammals, the air capillaries are not terminal fund sacs formations, and therefore allow an unidirectional air flow through the lungs of birds [30, 77, 80, 87].

The lung air sacs are pair formations, and their total number for the two lungs varies between 6 and 14 depending on the species, are generally referred to as cranial group and caudal group, and all cranial bags communicate with all secondary bronchi, fact that does not occur with caudal bags $[37,76,91]$. The oxygen concentration is higher inside the caudal bags whereas the concentration of carbon dioxide reaches higher values inside the cranial bags. This qualitative difference is explained by the particular pattern of unidirectional airflow that occurs in the lungs of birds [80].

The inhaled air moves into the respiratory system, whenever the chest cavity expands by the action of inspiratory muscles, and during expiration the air is expelled by action of the expiratory muscles. Although the birds do not have diaphragm, the entry and exit of air in to the respiratory system is a process similar to the observed in mammals.

During inhalation, air flows through the mesobronchus in to the posterior air sacs, and at the same time, the air enters the anterior air sacs via the dorsal secondary bronchus and parabronchus. During exhalation, the air leaves the posterior air sacs and passes through the parabronchus, and to a lesser extent, through the mesobronchus, to the trachea. At the same time in the anterior air sacs, the air moves through the secondary ventral bronchus towards the trachea. There is 
thus, during the two phases of the respiratory cycle, a continuous unidirectional flow through the parabronchus $[80,91]$.

The flow inside the air capillaries and inside the blood capillaries occurs in opposite directions, i.e., in the blood capillaries the flow goes from the most peripheral areas of the parabronchus into its axis, while in the air capillaries move away from the axis of parabronchus. It is established a counter-current system of gas exchange between air capillaries and blood capillaries [77, 80, 83].

Briefly we can say that the anatomical and physiological features that have just been summarily exposed, such as a continuous and unidirectional ventilation of parabronchus, lower capacity of the air sacs, large surface for gas exchange and a very thin air-blood barrier, explain the unique characteristics of the respiratory system of birds, allowing them to extract oxygen from the highly rarefied air atmosphere.

\section{RESPIRATORY SYSTEM IN MAMMALS}

Some 300 million years ago, the ancestors of modern reptiles finally emerged completely from water and made a commitment to air breathing. From them, developed the two great classes of vertebrates with high maximal oxygen consumption: the mammals and the birds. A remarkable feature of these two groups is that although the cardiovascular, renal, gastrointestinal, endocrine and nervous systems

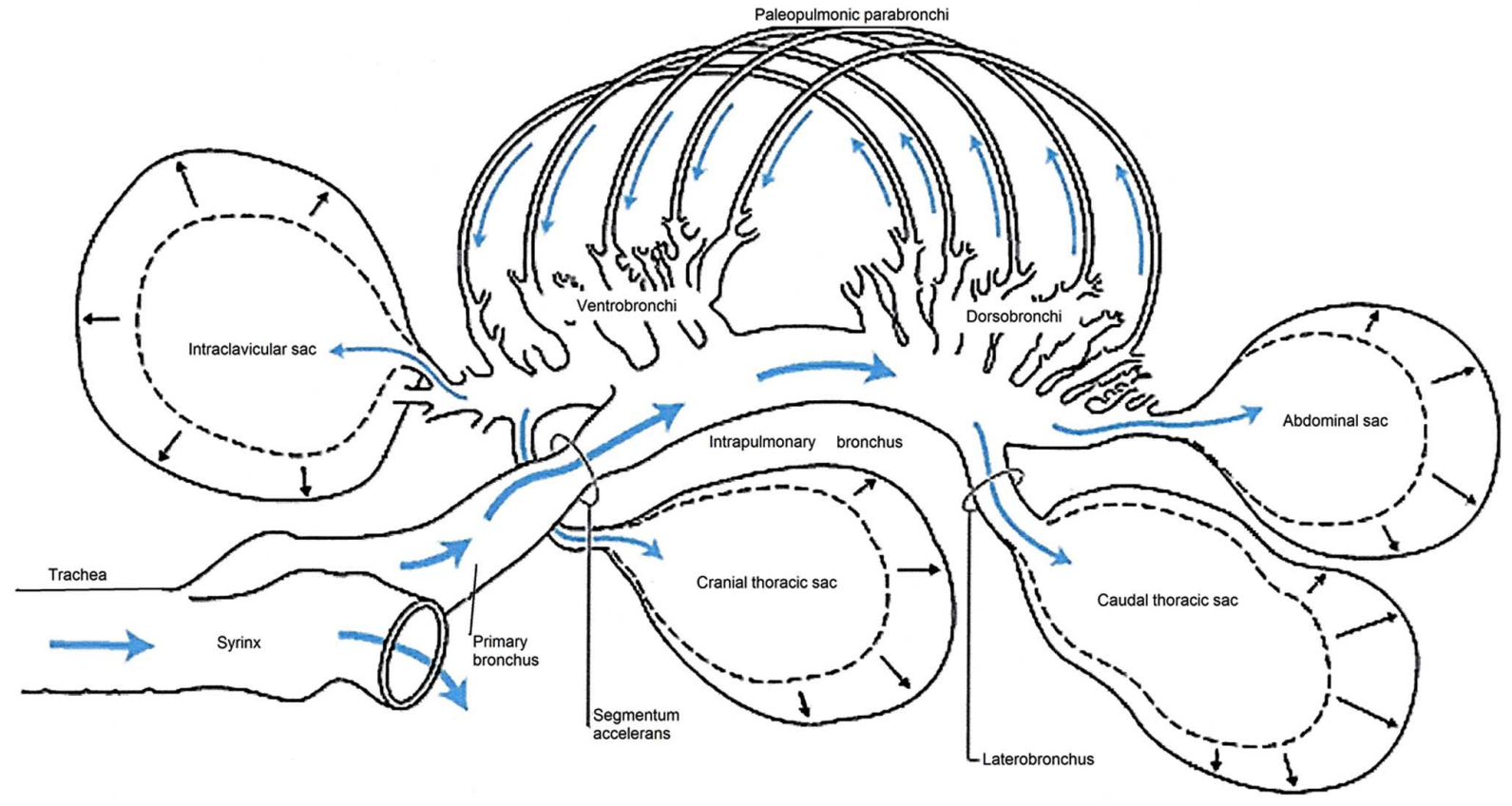

A

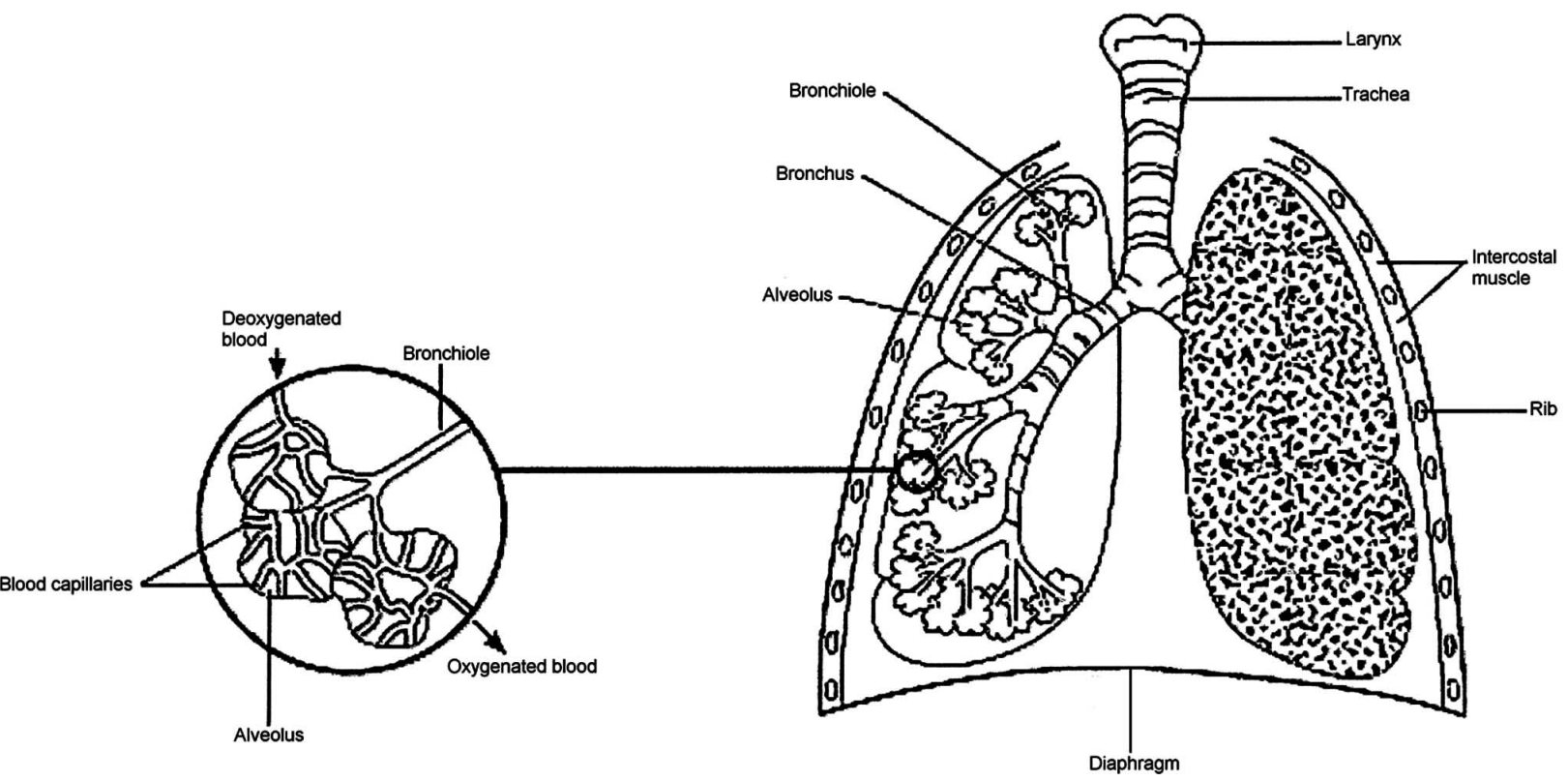

B

Fig. (3). Comparation between the birds (A) and mammals (B) respiratory systems. 
show many similarities, the lungs are radically different [93]. The distinct morphology of avian and mammalian lungs reflects not only an increased demand for gas exchange, but is historically correlated with the divergent modes of locomotion that facilitate higher rates of ventilations [94].

It is thought that mammals made their appearance on Earth during the Jurassic Period, the age of reptiles, when the process of divergence of the continents begun $[11,56]$.

Mammals evolved homoiothermy independently from birds, but in a very similar way. For the mandatory increased metabolism, they required a correspondingly increased gas exchange surface, which became available by the development of the broncho-alveolar lung.

The nearest ancestors of mammals appear to have been same group of reptiles and the lung of the mammals derived from a multicameral reptilian lung with three rows of lung chambers. The branched conducting bronchial system originated by stepwise further subdivision of these lung chambers, terminating in the branched respiratory bronchioli and ductus, covered with alveoli [37].

Of all tetrapods' breathing systems, the mammals' respiratory system has been the most extensively studied, often with the aim to acquire knowledge with medical relevance.

In mammals there is no dissociation between locomotion and respiratory movements and both are closely coupled especially during exercise.

The strong musculature of the diaphragm does not only act as a forceful inspiratory muscle together with the intercostals musculature, but is also responsible for maintaining a pressure gradient between the pleural and the peritoneal activity during strong exercise [95]. During respiration at rest, expiration is performed by elastic retractile forces of the extended rib cage and by the retraction forces of the lung itself out of the surface tension of the alveoli together with their extended elastic fibre systems. During exercise, expiratory movement of the intercostals musculature is strongly supported by the muscles of the abdominal wall, which is also the case for all sound productions, speech and singing [93].

In mammals the lungs do not empty completely during the expiration, and the result is that convective flow alone cannot take the inspired gas to the periphery of the lung where some of the gas-exchanging alveoli are located. Instead the last part of the distance is accomplished by a relatively large peripheral airways to allow mixing of the inspired air with that already in the lung, and the resulting large alveoli cause additional problems [92].

In the mammalian lung, the airway and vascular systems form a complex multigenerational dichotomous branching tree-like arrangement [96]. Transported by bulk-flow (convention) in the initial (large) parts of the bronchial system and mainly by diffusion in the terminal (fine) sections of the airway system, the inspired air ultimately reaches the alveoli where it is exposed to capillary blood across a thin, extensive tissue barrier [14].

The alveolar surface is mainly lined by type I and type II cells. Type II cells secrete surfactant.
In mammals the capillaries are located in the alveolar walls which are widely separated from each other. Thus the BGB has to withstand the full transmural pressure [92]. The capillary is typically polarized with one side having very thin BGB whereas on the other side the barrier is thicker [92] and contains strands of type collagen which provides support for the alveolar wall and maintains the integrity of the alveoli [97]. In contrast to an uniform thin BGB in the birds, in mammals half of the surface area of the capillaries provides inefficient gas exchange due to its increased thickness (Fig. 3).

\section{REFERENCES}

[1] Peretó J. Controversies on the origin of life. Int Microbiol 2005; 8: 23-31.

[2] Maina JN. Comparative respiratory morphology: themes and principles in the design and construction of the gas exchangers. Anat Rec (New Anat) 2000; 261: 25-44.

[3] Forterre P. Looking for the most "primitive" organism(s) on Earth today: the state of the art. Planet Space Sci 1995; 43: 167-77.

[4] Eigen H, Lindemann BF, Tietze M, et al. How old is the genetic code? Statistical geometry of the tRNA provides an answer. Science $1989 ;$ 244: 673-79.

[5] Gribaldo S, Brochier-Armanet C. The origin and evolution of Archae: a state of the art. Philos Trans R Soc B 2006; 361: 100722.

[6] Owen T, Cess RD, Ramanathan V. Enhanced CO2 greenhouse to compensate for reduced solar luminosity on early Earth. Nature 1979; 277: 640-1.

[7] Castresana J, Saraste M. Evolution of energetic metabolism: the respiration-early hypothesis. Trends Biochem Sci 1995; 20: 443-8.

[8] Schopf JW. The evolution of the earliest cells. Sci Am 1978; 239: 85-103.

[9] Alberts B, Bray D, Lewis J, et al. Molecular biology of the cell, Garland Publishing Inc., New York 1994; pp. 218-34.

[10] Grunwald DJ. A fin-de siècle achievement: Charting new wares in vertebrate biology. Science 1996; 274: pp. 1634-5.

[11] Weichert CK, Presch W. Elements of chordate anatomy, McGrawHill Book Company, New York 1986; pp. 209-45.

[12] Maina JN. Fundamental structure aspects and features in the bioengineering of the gas exchangers: comparatives perspectives. Adv Anat Embryo Cell Biol 2002; 163: 1-108.

[13] Atwood WH. In: Bahar LS, Johnston B, Eds Collier's encyclopedia, Maxwell Macmillan International Publishing Group, New York, Oxford, Singapore, Sydney 1992; pp. 137-66.

[14] Maina JN. Structure, function and evolution of the gas exchangers: comparative perspectives. J Anat 2002; 201: 281-304.

[15] Gray H. In: Bannister LH, Berry MM, Collins P, Dyson M, et al., Eds. Gray's anatomy, Churchill Livingstone 1995; pp. 1627-82.

[16] Moore KL, Persaud TVN. Before we are born. Essentials of embryology and birth defects, W.B- Saunders Company 1998; pp. 241-54.

[17] Schoenwolf GC, Bleyl SB, Brauer PR, et al. In: Larsen's Human Embryology, Churchill Livingstone 2009; pp. 319-36.

[18] Evans DH, Piermarini PM, Choe KP. The multifunctional fish gill: dominant site of gas exchange, osmoregulation, acid-base regulation, and excretion of nitrogenous waste. Physiol Rev 2005; 85: 97-177.

[19] Perry SF. The chloride cell: structure and function in the gills of freshwater fishes. Ann Rev Physiol 1997; 59: 325-47.

[20] Laurent P, Dunel S. Morphology of gill epithelia in fish. Am J Physiol 1980; 238: R147-159.

[21] Kudo H, Kato A, Hirose S. Fluorescence visualization of branchial collagen columns embraced by pillar cells. J Histochem Cytochem 2007; 55: 57-62.

[22] Olson KR. Vascular anatomy of the fish gill. J Exp Zool 2002; 293: 214-31.

[23] Wilson JM, Laurent P. Fish gill morphology: inside out. J Exp Zool 2002; 293: 192-213.

[24] Kato A, Nakamura K, Kudo H, et al. Characterization of the column and autocellular junctions that define the vasculature of gill lamellae. J Histochem Cytochem 2007; 55: 941-53. 
[25] Mistry AC, Kato A, Tran YH, et al. FHL5, a novel actin-binding protein, is highly expressed in eel gill pillar cells and responds to wall tension. Am J Physiol 2004; 287: R1141-54.

[26] Dunel-Erb S, Bailly Y, Laurent P. Neuroepithelial cells in fish gill primary lamellae. J Appl Physiol 1982; 53: 1342-53.

[27] Bailly Y, Dunel-Erb S, Laurent P. The neuroepithelial cells of the fish gill filament: indolamine-immunocytochemistry and innervation. Anat Rec 1992; 233: 143-61.

[28] Foskett JK, Scheffey C. The chloride cell: definitive identification as the salt-secretory cell I teleosts. Science 1982; 215: 164-6.

[29] Claiborne JB, Edwards SL, Morrison-Shetlar AI. Acid-base regulation in fishes: cellular and molecular mechanisms. J Exp Zool 2002; 293: 302-19.

[30] Nielsen KS. How Birds Breathe. Sci Am 1971; 225: 72-9.

[31] Herbing IH, Miyake T, Hall BK, Boutilier RG. Ontogeny of feeding and respiration in larval atlantic cod Gadus morhua (Teleostei, Gadiformes): I. Morphology. J Morphol 1996; 227: 1535.

[32] Herbing IH, Miyake T, Hall BK, Boutilier RG. Ontogeny of feeding and respiration in larval atlantic cod Gadus morhua (Teleostei, Gadiformes): II. Function. J Morphol 1996; 227: 37-50.

[33] Liem KF. The biology of lungfishes: an epilogue. J Morphol 1986; 1:299-303.

[34] Clack JA. Earliest known tetrapod braincase and the evolution of the stapes and fenestra ovalis. Nature 1994; 369: 392-4.

[35] Zhu M, Yu X. A primitive fish close to the common ancestor of tetrapods and lungfish. Nature 2002; 418: 767-70.

[36] Daeschler EB, Shubin NH, Jenkins FA Jr. A Devonian tetrapodlike fish and the evolution of the tetrapod body plan. Nature 2006; 440: 757-63.

[37] Duncker H. Vertebrate lungs: structure, topography and mechanics. A comparative perspective of the progressive integration of respiratory system, locomotor apparatus and ontogenic development. Respir Physiol Neurobiol 2004; 144: 111-24.

[38] Bemis WE, Burgreen WW. The biology and evolution of lungfishes. J Morphol 1986; 1: 3-4.

[39] Kemp A. The biology of the Australian lungfish, Neoceratodus forsteri (Krefft 1870). J Morphol 1986; 1: 181-98.

[40] Power JHT, Doyle IR, Davidson K, Nicholas TE. Ultrastructural and protein analyses of surfactant in the Australian lungfish Neoceratodus forsteri: evidence for conservation of composition for 300 million years. J Exp Biol 1999; 202: 2543-50.

[41] Shelton G. The regulation of breathing. Fish Physiol 1970; 4: 293359.

[42] Burggren WW, Johansen K. Circulation and respiration in lungfishes (Dipnoi). J Morphol 1986; 1: 217-36.

[43] Greenwood PH. The natural history of African lungfishes. J Morphol 1986; 1: 163-79.

[44] Fishman AP, Pack AI, Delaney RG, Galante RJ. Estivation in Protopterus. J Morphol 1986; 1: 237-48.

[45] Perry SF, Euverman R, Wang T, et al. Control of breathing in African lungfish (Protopterus dolloi): a comparison of aquatic and cocooned (terrestrialized) animals. Respir Physiol Neurobiol 2008; 160: 8-17.

[46] Lenfant C, Johansen, K. Respiration in the African lungfish Protopterus aethiopicus. I. respiratory properties of blood and normal patterns of breathing and gas exchange. J Exp Biol 1968; 49: 437-52.

[47] Sacca R, Burggren W. Oxygen uptake in air and water in the airbreathing redfish Calamoichthys calabaricus: role of the skin, gills and lungs. J Exp Biol 1982; 97: 179-86.

[48] de Moraes MFPG, Holler S, da Costa OTF, et al. Morphometric comparison of the respiratory organs in the South American lungfish Lepidosiren paradoxa (Dipnoi). Physiol Biochem Zool 2005; 78: 546-59.

[49] Long JA, Gordon MS. The greatest step in vertebrate history: a paleobiological review of the fish-tetrapod transition. Physiol Biochem Zool 2004; 77: 700-19.

[50] Graham JB, Lee HJ. Breathing air in air: in what ways might extant amphibious fish biology relate to prevailing concepts about early tetrapods, the evolution of vertebrate air breathing, and the vertebrate land transition? Physiol Biochem Zool 2004; 77: 720-31.

[51] Randall DJ, Burgreen WW, Farrel AP, Haswell D. The evolution of air breathing in vertebrates. Cambridge University Press 1981; pp. $133-50$.
[52] Brainerd EL, Owerkowicz T. Functional morphology and evolution of aspiration breathing in tretapods. Respir Physiol Neurobiol 2006; $154: 73-88$.

[53] Hughes GM. Species variation in gas exchange. Proc R Soc Med 1966; 59: 494-500.

[54] Dejours P. From comparative physiology of respiration to several problems of environmental adaptations and to evolution. J Physiol 1989; 410: 1-19.

[55] Howell BJ. Acid-base balance in transition from water breathing to air breathing. Fed Proc 1970; 29: 1130-4.

[56] Véron G. Organisation et classification du règne animal, Eds. Nathan, Paris 1995.

[57] Lenfant C, Johansen K, Hanson D. Bimodal gas exchange and ventilation-perfusion relationship in lower vertebrates. Fed Proc 1970; 29: 1124-9.

[58] Carrier DR, Wake MH. Mechanism of lung ventilation in the Caecilian Dremophis mexicanus. J Morphol 1995; 226: 289-95.

[59] Gatz RK, Crawford EC, Piiper J. Respiratory properties of the blood of lungless and gill-less salamander, Desmognathus fuscus. Respir Physiol 1974; 20: 33-41.

[60] Piiper J. Respiratory gas exchange at lungs, gills and tissues: mechanisms and adjustsments. J Exp Biol 1982; 100: 5-22.

[61] Maina JN, Maloiy GMO. A scanning and transmission electron microscopic study of the lung of a caecilian Boulengerula taitanus. J Zool (Lond) 1988; 215: 739-51.

[62] Stark-Vancs V, Bell PB, Hutchson VH. Morphological and pharmacological basis for pulmonary ventilation in Amphiuma tridactylum: an ultrastructural study. Cell Tissue Res 1984; 238: 112.

[63] Hughes GM, Vergara GA. Static pressure-volume curves for the lung of the frog (Rana pipiens). J Exp Biol 1978; 76: 140-65.

[64] Fleetwood JN, Munnell JF. Morphology of the airways and lung parenchyma in hatchlings of the loggerhead sea turtle, Caretta caretta. J Morphol 1996; 227: 289-304.

[65] Perry SF. Reptilian lungs: functional anatomy and evolution. Adv Anat Embryol Cell Biol 1983; 79: 1-81.

[66] Kooyman GL. Respiratory adaptations in marine animals. Am Zool 1973; 13: 457-68.

[67] Castells MT, Ballesta J, Pastor LM, et al. Histochemical characterization of glyconjugates in the epithelium of the extrapulmonary airways of several vertebrates. Histol J 1990; 22: 24-35.

[68] Pastor LM, Ballesta J, Hernandez F, et al. Microscopic study of the tracheal epithelium of Testudo graeca e Pseudemys scripta elegants. J Anat 1987; 153: 171-83.

[69] Pastor LM, Ballesta J, Castels MT, et al. A light and electron microscopic study of the epithelium of the extrapulmonary airways of Mauremys caspica and Lacerta lepida (Reptilia). J Submicrosc Cytol Pathol 1988; 20: 25-36.

[70] Perry SF. Functional morphology of the lungs of the Nile crocodile, Crocodylus niloticus: non-respiratory parameters. J Exp Biol 1988; 134: 99-117.

[71] Solomon SE, Purton M. The respiratory epithelium of the lung in the green turtle (Chelonia mydas L.). J Anat 1984; 139: 353-70.

[72] Kikkawa Y, Motoyama EK, Cook CD. The ultrastructure of the lungs of lambs: the relation of osmiophilic inclusions and alveolar lining layer to fetal maturation and experimentally produced respiratory distress. Am J Pathol 1965; 47: 877-903.

[73] Askin FB, Kuhn C. The cellular origin of pulmonary surfactant. Lab Invest 1971; 25: 260-8.

[74] Maina JN. What it takes to fly: the structural and functional respiratory refinements in birds and bats. J Exp Biol 2000; 203: 3045-64.

[75] Tucker VA. Respiratory physiology of house sparrows in relation to high altitude flight. J Exp Biol 1968; 48: 55-66.

[76] Lasiewski RC. Respiratory function in birds. Avian Biol 1972; II 287-342.

[77] Maina JN. Scanning electron microscope study of the spatial organization of the air and blood conducting components of the avian lung (Gallus Gallus variant domesticus). Anat Rec 1988; 222: 145-53.

[78] Scott GR, Cadena V, Tattersall GJ, Milsom WK. Body temperature depression and peripheral heat loss accompany the metabolic and ventilatory responses to hypoxia in low and high altitude birds. J Exp Biol 2008; 211: 1326-35. 
[79] Scott GR, Milsom WK. Control of breathing and adaptation to high altitude in bar-headed goose. Am J Physiol 2007; 293: R379-91.

[80] Scheid P. Respiration and control of breathing. Avian Biol 1982; VI: 405-53.

[81] Maina JN. Developmental dynamics of the bronchial (airway) and air sac system of the avian respiratory system from day 3 to day 26 of life: a scanning electron microscope study of the domestic fowl, Gallus gallus variant domesticus. Anat Embryol 2003; 207: 119-34.

[82] Tickle PG, Ennos AR, Lennox LE, et al. Functional significance of the uncinate processes in birds. J Exp Biol 2007; 210: 3955-61.

[83] Banks WJ. In: Applied veterinary histology, Williams and Wilkins, Baltimore, Hong Kong, London, Sydney 1986; pp. 447-66.

[84] Thompson MB. Comparison of the respiratory transition at birth or hatching in viviparous and oviparous amniote vertebrates. Comp Biochem Physiol 2007; 148: 755-60.

[85] Akester AR. The comparative anatomy of the respiratory pathways in the domestic fowl (Gallus domesticus) pigeon (Columbia livia) and domestic duck (Anas platyrhyncha). J Anat 1960; 94: 487-505.

[86] King AS, Cowie AF. The functional anatomy of the bronchial muscle of the bird. J Anat 1969; 105: 323-36.

[87] Klika E, Scheurermann DW, De Groodt-Lasseel MHA, et al. Pulmonary macrophages in birds, Barn Owul, (Tyto tyto alba) Domestic Fowl (Gallus, gallus f. domestica) Quail (Coturnix coturnix) and Pigeons (Columbia livia). Anat Rec 1996; 246: 8797.
[88] Lorz C, Lopez J. Incidence of air pollution in the pulmonary surfactant system of the pigeon (Columba livia). Anat Rec 1997; 249: 206-12.

[89] Scheuermann DW, Klika E, De Groodt-Lasseel MHA, et al. An electron microscopic study of the parabronchial epithelium in the mature lung of four bird species. Anat Rec 1997; 249: 213-25.

[90] Duncker HR. Structure of the avian respiratory tract. Respir Physiol 1974; 22: 1-19.

[91] Randall DJ. In: Animal physiology, R. Eckert, W.H. Freeman and Company, New York 1988; pp. 474-519.

[92] West JB, Watson RR, Fu W. The honeycomb-like structure of the bird lung allows a uniquely thin blood-gas barrier. Respir Physiol Neurobiol 2006; 152: 115-8.

[93] West JB, Watson RR, Fu W. The human lung: did evolution get it wrong? Eur Respir J 2007; 29: 11-7.

[94] Hicks JW, Farmer CG. Gas exchange potential in reptilian lungs: implications for the dinosaur-avian connection. Respir Physiol 1999; 117: 73-83.

[95] Duncker HR. The emergence of macroscopic complexity. An outline of the history of the respiratory apparatus of vertebrates from diffusion to language production. Zoology 2001; 103: 240-59.

[96] Maina JN, van Gils P. Morphometric characterization of the airway and vascular systems of the lung of the domestic pig, Sus scrofa: Comparison of the airway, arterial and venous systems. Comp Biochem Physiol 2001; 130: 781-98.

[97] Weibel ER. Morphological basis of alveolar-capillary gas exchange. Physiol Rev 1973; 75: 1097-109.

(C) Carvalho and Gonçalves; Licensee Bentham Open.

This is an open access article licensed under the terms of the Creative Commons Attribution Non-Commercial License (http://creativecommons.org/licenses/by$\mathrm{nc} / 3.0 /$ ), which permits unrestricted, non-commercial use, distribution and reproduction in any medium, provided the work is properly cited. 